\section{Caminhos cruzados: o papel de Frederico Simões Barbosa na constituição da Saúde Coletiva}

\author{
Crossed paths: the role of Frederico Simões \\ Barbosa in the constitution of Public Health
}

\author{
Caminos cruzados: el papel de Frederico Simões \\ Barbosa en la constitución de la Salud Pública
}

Nísia Trindade Lima ${ }^{1}$

preenchimento de tal lacuna, ao mesmo tempo em que reverencio a memória desse importante pesquisador brasileiro 1,2 .

Tomo como ponto de partida um pequeno trecho escrito por Moisés Goldbaum \& Rita Barradas Barata 3 (p. 80), publicado no livro Saúde Coletiva como Compromisso: A Trajetória da Abrasco: "Frederico Simões Barbosa foi um conceituado e respeitado parasitologista, com experiência em estudos populacionais de campo, representante de toda uma tradição da parasitologia brasileira de trabalhos em Saúde Pública. Associava a militância política pela saúde e pela renovação do ensino médico a uma atuação sólida e marcante como docente e pesquisador. Ninguém melhor para representar os anseios da nova associação".

Tradição em parasitologia, militância pela saúde, renovação do ensino médico e atuação sólida como pesquisador: estes são termos-chave para entendermos o percurso de Frederico Simões Barbosa e sua contribuição à saúde coletiva. Durante a década de 1970, ocorreu um importante encontro do pesquisador com a nova geração de sanitaristas dedicada ao projeto de reforma sanitária, que teria como marcos o capítulo dos direitos sociais na Constituição Federal de 1988 e a criação do Sistema Único de Saúde (SUS). Está ainda para ser escrita a história desses caminhos que se cruzaram e do encontro de duas gerações da saúde pública brasileira. Seja como discípulos ou como companheiros na construção institucional da saúde coletiva, mui- 
tos dos que viveram intensamente aqueles anos recordam Frederico Simões Barbosa e o reverenciam neste suplemento de homenagem publicado por CSP. Sem a força e a afetividade de um testemunho, este texto tem por objetivo apresentar alguns aspectos da trajetória do primeiro presidente da Abrasco, com ênfase na emergência de uma preocupação mais social nos estudos sobre endemias, além dos trabalhos em Planaltina (Distrito Federal), com o seu caráter inovador no ensino médico e na medicina comunitária. Destaco por fim a importância da contribuição do pesquisador para as agendas atual e futura da saúde coletiva.

\section{Da parasitologia médica à experiência inovadora em Planaltina}

Em depoimento a Carlos Coimbra Jr., Frederico Simões Barbosa atribui ao acaso o seu encaminhamento para a pesquisa em parasitologia. Estudante da Faculdade de Medicina do Recife, teve a oportunidade de assistir, em 1936, ao curso ministrado por Samuel Pessoa, professor convidado por aquela instituição de ensino. Daí teve início um contato mais próximo e, por meio de bolsa de estudo para a Universidade de São Paulo (USP), obtida junto a Assis Chateaubriand, dos Diários Associados, a possibilidade de se especializar em parasitologia e micologia, respectivamente sob a orientação de Samuel Pessoa e Floriano de Almeida. Dessa formação, resultaram no período inicial de carreira publicações no campo do estudo de fungos e sua correta classificação 4 .

Na década de 1940, com o apoio de bolsa de estudos do Institute of Interamerican Affairs, cursou o mestrado em Saúde Pública na Faculdade de Higiene e Saúde Pública da Universidade Johns Hopkins, tendo ainda aproveitado o período nos Estados Unidos para realizar estágios no Museu Nacional, em Washington DC, e na Universidade de Michigan. No depoimento citado, Frederico Simões Barbosa observa que as diferenças sociais e, em particular, a discriminação racial foram aspectos marcantes da estadia de dois anos nos Estados Unidos.

De acordo com Carlos Coimbra Jr., é possível identificar duas fases na carreira do pesquisador. Uma primeira dedicada à micologia e à entomologia médica, e uma segunda fase voltada para a malacologia médica, que o teria encaminhado para a epidemiologia da esquistossomose. Transição que coincidiu com o seu ingresso no recém-criado Centro de Pesquisas Aggeu Magalhães, no Recife 4 .

No campo da epidemiologia da esquistossomose, foram realizados estudos comparativos sobre a morbidade de esquistossomose em quatro localidades endêmicas de Pernambuco, e um importante estudo de comunidade longitudinal em Pontezinha, onde também realizou investigação sobre a eficácia de moluscicidas.

Um tópico de interesse é o recurso ao estudo de comunidade, modalidade de pesquisa bastante frequente naquele período, mas voltada predominantemente para a organização social e realizada por antropólogos e sociólogos 5 . No caso do trabalho em Pontezinha (Pernambuco), Frederico Simões Barbosa contou com o apoio de três assistentes sociais para as atividades de campo, indicadas por Hortênsia Holanda, educadora do Ministério da Saúde. Sobre o reconhecimento da pesquisa, ele observou na já citada entrevista: "De fato, o trabalho em Pontezinha foi vanguarda porque, na época, estavam todos olhando apenas para o controle químico. Contudo, não recebeu muito crédito, principalmente no exterior. A ênfase das pesquisas centrava-se mais no vetor elou no parasita. Trabalhos de comunidade não gozavam de muito prestígio. Acho mesmo que este foi o primeiro estudo que se preocupou realmente em trabalhar com a comunidade a questão do controle..." 4 (p. 151).

Preocupação semelhante com estratégias de controle alternativas ao controle químico orientou suas ações na Organização Mundial da Saúde (OMS), organismo em que coordenou o programa de esquistossomose de 1969 a 1971. Em seu depoimento, o pesquisador relata as pressões sofridas durante o período: "Bem, a OMS é um órgão extremamente político. Havia muita pressão por parte de certas empresas. Por exemplo, naquela época havia grande interesse no uso de moluscicidas que, quase sempre, eram preconizados como medida única de controle. Opus-me a colaborar com esse esquema e cheguei a ser muito pressionado para dar pareceres etc." 4 (p. 152).

De volta ao Brasil, Frederico Simões Barbosa foi para a Universidade de Brasília (UnB) e implantou em Planaltina um novo modelo de medicina comunitária baseada no princípio de integração docente-assistencial. Foi uma rica experiência interrompida bruscamente pela reitoria, no contexto do regime militar. Foram criados o internato e a residência em medicina preventiva e defendidas duas dissertações de mestrado analisando, respectivamente, aspectos clínicos e epidemiológicos da giardíase entre crianças e a atenção à saúde infantil no Programa Planaltina. Esse último trabalho resultou da pesquisa realizada por José Paranaguá de Santana, que se tornaria posteriormente uma referência na área de educação e formação de recursos humanos em saúde.

Contratado em 1981 como assessor da antiga Coordenadoria de Ciências da Saúde da Secre- 
taria de Educação Superior do então Ministério da Educação e Cultura (MEC), coordenou, em Brasília, a elaboração do Programa de Integração Docente-Assistencial do MEC, que teve por objetivo estimular o desenvolvimento de projetos de integração docente-assistencial nas universidades brasileiras, visando a inserir a formação de profissionais da área da saúde nas realidades regional e nacional 6,7 .

Dois anos antes havia assumido a presidência da Abrasco, numa diretoria que teve como secretário executivo Paulo Buss, então jovem docente e coordenador da residência em Saúde Pública da Escola Nacional de Saúde Pública (ENSP). Nessa unidade da Fundação Oswaldo Cruz (Fiocruz), durante a gestão de Sergio Arouca (19851989), foram realizadas as primeiras eleições diretas para o cargo de diretor. Frederico Simões Barbosa, que havia ingressado na instituição em 1983 como professor de epidemiologia, e Paulo Buss foram eleitos, respectivamente, diretor e vice-diretor da ENSP. Nas palavras de Buss, o primeiro diretor eleito naquela unidade era um decano e a experiência na renovação da educação médica na UnB o colocava como um ator que, vinculado a uma saúde pública mais tradicional orientada por intervenções técnicas qualificadas, trazia para a escola sua experiência inovadora no campo da integração docente-assistencial. Durante a sua gestão na ENSP, entre outras medidas importantes, foram intensificadas as ações de pesquisa, fortalecidas a pós-graduação e a qualificação do corpo docente, com intenso programa de formação de doutores, inclusive no exterior 8 .

\section{Uma agenda para a saúde coletiva}

Historiadores e cientistas sociais que vêm se dedicando ao estudo de biografias, têm apontado problemas recorrentes na busca por interpretar o papel dos indivíduos em diferentes contextos sociais. Entre outras perspectivas, destaca-se a de Pierre Boudieu ao discutir o fenômeno da "ilusão biográfica” 9. De forma muito simplificada, pode-se afirmar que tal distorção de análise ocorre quando se pretende atribuir sentido a uma experiência individual e narrar a trajetória de uma pessoa, identificando etapas marcadas por uma "missão de vida" apreensível numa retrospectiva.

Embora não seja minha intenção traçar um caminho pré-definido e exemplar, e incorrer no equívoco apontado por Bourdieu, defendo que reconhecer o papel de tradições intelectuais e de formação para a saúde nos ajuda a refletir sobre o papel dos que construíram este campo de teorias e práticas. Esse é o caso de Frederico Simões Barbosa, cuja trajetória é marcada por experiências inovadoras e de interesse para a agenda contemporânea de saúde coletiva.

Um primeiro aspecto a observar é o recurso à interdisciplinaridade. Ainda que não tenha realizado pesquisa que me permita afirmar a importância da perspectiva de Samuel Pessoa nos trabalhos de Frederico Simões Barbosa, é possível falar de uma tradição de parasitologia brasileira pautada pela convergência de conhecimento biomédico e explicações sociais. É o que se pode constatar nos trabalhos de Pessoa sobre habitação rural, que são fontes essenciais para obras seminais, a exemplo de Os Parceiros do Rio Bonito, de Antonio Candido. Essa orientação interdisciplinar esteve presente, entre outras iniciativas, ao se criar na ENSP o Núcleo de Endemias Samuel Pessoa, posteriormente transformado em departamento, com o objetivo de ser um espaço interdisciplinar voltado ao estudo dos determinantes e das estratégias de controle do processo saúde/ doença em sua dimensão coletiva.

A segunda chave de leitura a que fiz referência foi a militância política pela saúde e aqui destaco, entre outros aspectos, a agenda ambiental de extrema relevância na contemporaneidade. $\mathrm{O}$ estudo de comunidade realizado em Pontezinha e os relatórios como coordenador do programa de esquistossomose da Organização Pan-Americana da Saúde (OPAS) sobre o uso de molucicida em países africanos, constituem contribuições que vão além de um interesse na reconstituição da saúde pública dos anos 60 e 70 do século passado. São referências importantes para o que se discute e se propõe atualmente acerca de controle de vetores, saúde e ambiente.

Em terceiro lugar, o papel de Frederico Simões Barbosa na renovação do ensino médico e nas propostas de integração docente-assistencial é de grande relevância e atualidade, além de ter contribuído para a formação de sanitaristas que vêm atuando, desde um ponto vista crítico, no campo da formação de recursos humanos em saúde.

Após a morte do pesquisador, ocorrida em 2004, Constança Simões Barbosa doou à Casa de Oswaldo Cruz (Fiocruz) o arquivo de seu pai 10. Ao reunir documentos textuais e fotografias relacionados à trajetória profissional, à produção intelectual e às múltiplas atividades de seu titular, o rico acervo pode ser consultado hoje por todos os que se sentem desafiados a estudar o processo de formação de tradições científicas e de intervenção social e, com isto, alargar a imaginação sobre o presente e o futuro da saúde. 
1. Lima NT, Santana JP, organizadores. Saúde coletiva como compromisso: a trajetória da Abrasco. Rio de Janeiro: Editora Fiocruz/Abrasco; 2006.

2. Lima NT, Santana JP, Paiva CHA. Saúde coletiva: a Abrasco em 35 anos de história. Rio de Janeiro: Editora Fiocruz/Abrasco; 2015.

3. Goldbaum M, Barata RB. O feito por fazer. In: Lima NT, Santana JP, organizadores. Saúde coletiva como compromisso: a trajetória da Abrasco. Rio de Janeiro: Editora Fiocruz/Abrasco; 2006. p. 79-112.

4. Coimbra Jr. CEA. Uma conversa com Frederico Simões Barbosa. Cad Saúde Pública 1997; 13:145-55.

5. Oliveira NS, Maio MC. Estudos de comunidade e ciências sociais no Brasil. Sociedade e Estado 2011; 26:521-50.

6. Coutinho EM. Frederico Adolfo Simões Barbosa (1916-2004). Rev Soc Bras Med Trop 2004; 37:427-8.

7. Pires-Alves FA, Paiva CHA. Recursos críticos: história da cooperação técnica Opas-Brasil em recursos humanos para a saúde (1975-1988). Rio de Janeiro: Editora Fiocruz; 2006.
8. Casa de Oswaldo Cruz, Fundação Oswaldo Cruz. Depoimento de Paulo Buss a Nísia Trindade Lima, Cristina Fonseca, Paulo Elian e Verônica Brito. Projeto: Uma Escola para a Saúde: 50 anos da ENSP. Rio de Janeiro: Casa de Oswaldo Cruz, Fundação Oswaldo Cruz; 2003/2004.

9. Bourdieu P. A ilusão biográfica. In: Ferreira MM, Amado J, organizadoras. Usos e abusos da história oral. Rio de Janeiro: Editora FGV; 1998. p. 183-91.

10. Santos PRE, Mesquita CC, Cruz APM, Reis NRB, Lourenço FS. Saúde pública e ações comunitárias no arquivo Frederico Simões Barbosa. Patrimônio e Memória 2007; 3:160-8. 